\title{
Contrast Sensitivity Studies and Test- Review
}

\author{
Pateras $\mathrm{E}^{1 *}$ and Karioti $\mathbf{M}^{2}$ \\ ${ }^{1}$ Associate Professor, Biomedical Department, Course of Optics and Optometry, Greece \\ ${ }^{2}$ Msc Student, Biomedical Department, Course of Optics and Optometry, Greece
}

*Corresponding author: Pateras E, Associate Professor, Biomedical Department, Course of Optics and Optometry, Athens, Greece

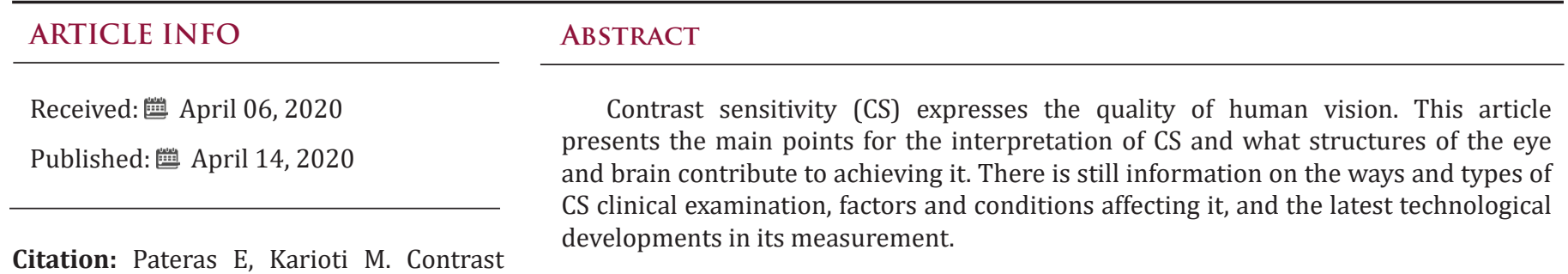

Sensitivity Studies and Test- Review. Biomed J Sci \& Tech Res 27(1)-2020. BJSTR.

Keywords: Visual Contrast Sensitivity; Visual Acuity; Magno; Parvo; Pelli-Robson MS.ID.004439.

\section{Introduction}

Visual acuity (V.A.) is the measure of the spatial resolution of the eye (the clarity or sharpness of vision) and its measurement determines the highest spatial frequency or smallest detail that the eye can perceive at high levels of contrast [1,2]. But V.A. is measured on a fixed target (optotype) and it may be the basic assessment of vision but does not fully meet the daily requirements of the human visual function, which comes into contact with a variety of stimuli of varying intensity. Contrast sensitivity (C.S.) is the ability of the eye to detect small changes in illumination at targets that do not have clearly defined limits [3]. Measuring C.S. is just as important as V.A. and is now universally accepted as complementary [1]. as it reflects the quality of vision and in many cases declines earlier, while V.A. remains normal (6/6 or better) [3]. C.S. defines the threshold between visible and non-visible, which has both elementary and clinical significance in the science of vision. From the point of view of physics, most light stimuli can be analyzed in a series of sine waves (Fourier analysis -1822) [4-6]. To compare the performance of optical systems, a commonly used measure is the modulation transfer function (MTF). For example, the MTF of a lens is its ability to transfer contrast at a particular resolution from the object to the image. So MTF is a way to incorporate resolution and contrast into a single specification. As line spacing decreases on a line test target, it is difficult for the lens to transfer this decrease in contrast while MTF decreases. However, MTF does not correspond fully to analyze the contrast of the image created in the human visual system [7].
A more complete description of the spatial resolution of the optical system of the eye is given by the curve of the spatial contrast sensitivity function (CSF) $[2,8]$. The CSF curve describes the size of the object in relation to the spatial frequency (c/deg) of a sine wave [8]. and this corresponds to the actual V.A. of the person. [2]. Similarly, the graph of the time frequency as a function of pulse light (flashing) is given [2]. The first scientist that calculated the optical contrast sensitivity as a function of spatial frequency was Schade (1956) [9]. One of the most important terms for studying CSF is spatial frequency. The number of cycles of an image falling over a certain spatial distance, usually one degree of angle of vision, is the spatial frequency [4]. It is the measure that determines the clarity and gradation of the bright and dark areas. The representation consists of a light and a dark region, for example in a sine wave. [4]. The high spatial frequency representation comprises many narrow lines, that means, many circles within each degree of angle-cycles per degree (cpd), while at low frequencies the lines widen, so the cycles are less per degree. [4]. Spatial frequency can also be set with respect to the observation distance, so as the distance decreases each line increases, so the frequency decreases. [4]. The highest spatial frequency of human perception is $30 \mathrm{c} / \mathrm{deg}$ and corresponds to approximately V.A. 6/6. [6]. CS depends on the function, anatomy and distribution of the optic nerve axons. Starting from the region of the retina where the photoreceptors are located, phototransmission converts light energy into electrical signals. dipole cells and 
ganglion cells. The axons of the ganglion cells form the optic nerve. [10]. The main nodal points of electrical signals as they travel to the visual cortex of the brain are photoreceptors (cones and rods), dipoles and ganglion cells. The axons of the ganglion cells form the optic nerve (Figures $1 \& 2$ ).

(a)

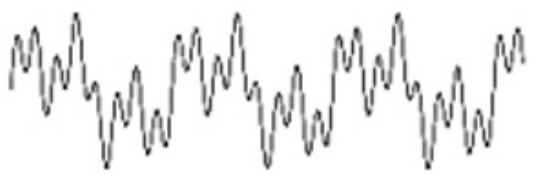

(b)

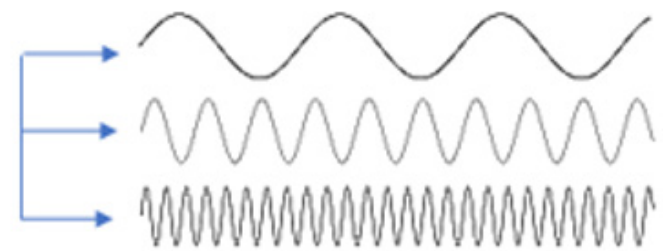

Figure 1:

(a) Fourier analysis of a complex wave.

(b) This wave can breakdown into three simple sine waves.

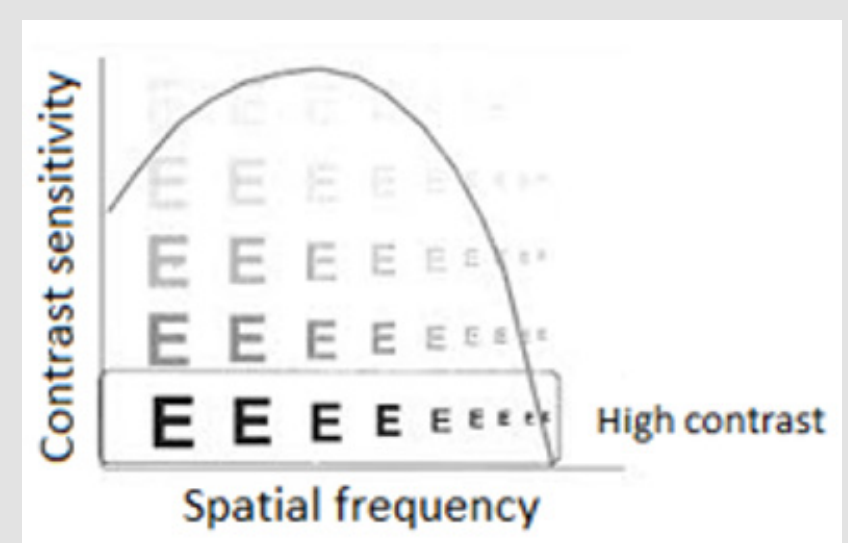

Figure 2: Contrast sensitivity function (CSF) curve.

The ganglion cells are divided into subgroups according to how they respond to light ((bright light or dark) - (response in the presence or absence of light)) and depending on the area of the lateral geniculate body they end up into two types of cells $[10,11]$. (Magni and Parvi / Large and Small). A third subclass of ganglion cells, which respond to S-cones, has recently been discovered, which percepts blue yellow. P cells make up $90 \%$ of the optic nerve and come from most of the macular fovea centralis. They have a small receptive field (excitation field from the photoreceptor region) and respond better to high spatial frequencies and color perception, but with a reduced CS. $([10,12,13]$. The $\mathrm{M}$ cells are few in number $(10 \%$ of the optic nerve) with a large but receptive field and thus have a reduced spatial resolution but have an increased CS. [10,12,13]. $\mathrm{M}$ and $\mathrm{P}$ cells continue their course to lateral geniculate nucleus (LGN). The lower layers pass through the $\mathrm{M}$ cells and form the Magnocellular pathway, and the P cells passing through the upper layers of the LGN form the Parvocellular pathway. The M and P paths end up at different points in the primary visual cortex, conveying different information from their beginning. The $\mathrm{M}$ path elaborates the motion and depth perception and the $\mathrm{P}$ path the perception of colors, shape and shapes. [10,12] Figures 3-5.

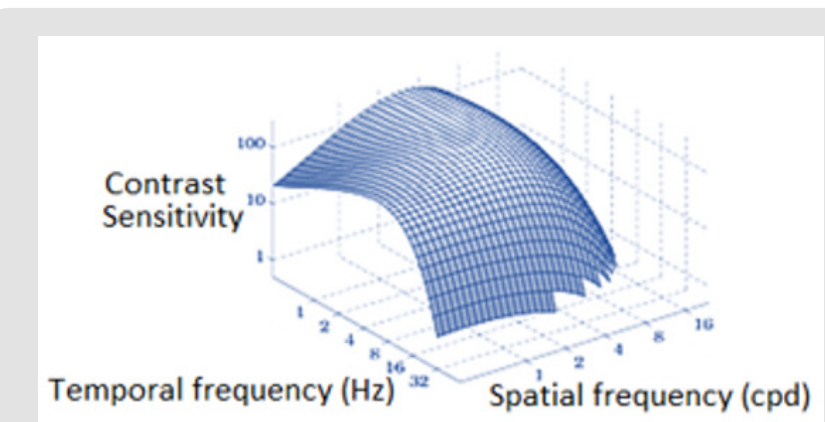

Figure 3: Spatial and temporal frequency combination in CSF.

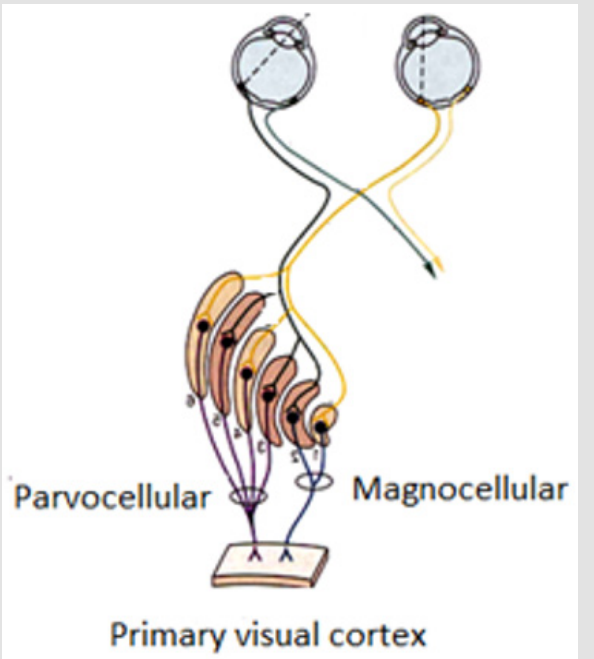

Figure 4: Magnocellular and Parvocellular pathway.

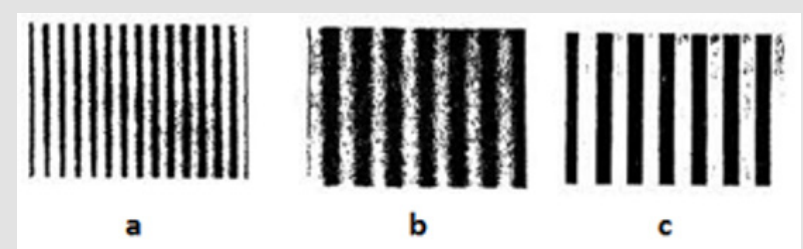

Figure 5: Arden grating chart of contrast sensitivity.

\section{Popular Tests for CS}

Bailey-Lovie: This test, in addition to accurate 00 measurement, is also used to evaluate CS. Due to the logarithmic size difference between the letters it comprises and the gaps between them in glare, it is possible to determine the CS of the examinee Measurement of Contrast Sensitivity CS as a term was first mentioned in 1860 (Fechner-Elemente der Psychophysik) and the first test for its measurement was published in 1918 (BJO). 
However, the first to make substantial subjective measurement of CS using sinusoidal grating patterns were Green and Campell in 1965 (Journal of Physiology). [1,9]. Furthermore, the Arden grating chart of contrast sensitivity, which consisted of vertical gratings of different spatial frequency, has been used in clinical practice since 1976. [14]. Measurements have since evolved, tests have been upgraded and refined, depending on the problem that needs analysis. The subjective examination of CS depends on the type of options the respondent has to answer. That is, there are free answer tests where the respondent states his or her answers until he or she cannot respond (e.g. Vistech) and forced answer tests where the respondent is forced to choose one of at least two alternative answers (e.g. Cambridge).CS measurement tables are divided into two main types, depending on the stimulus, [4]. on the grating charts for which the contrast of the targets is given by the Michelson equation:

$$
\frac{L_{\max }-L_{\min }}{L_{\max }+L_{\min }}
$$

and letter charts, which the contrast of the targets is given by the Weber equation:

$$
\frac{L_{\max }-L_{\min }}{L_{\text {background }}} \text { or } \frac{L_{\max }-L_{\min }}{L_{\max }}
$$

Where Lmax is the maximum illumination of the light areas of the chart, Lmin the minimum illumination of the dark areas, Lbackground the illumination of the background. $[9,15]$. Generally, today there is a variety of different optotypes used for CS testing but the two most widely used are the Vistech and the Pelli-Robson. The Pelli-Robson chart consists of letters of equal size, in sixteen triples, with a decrease in brightness of $0.15 \log$ units per triple. $[4,5,16]$. The test is set one meter from the person examined and the letter size is $4.9 \times 4.9 \mathrm{~cm}$ and consists of eight rows of letters. $[4,5,17]$. The PelliRobson test is easy to use as it resembles the V.A. measurement that most patients are familiar with, its fast and with good repeatability. $[5,15]$. It is ideal for cataract detection, screening of patients with intraocular lenses and for checking drivers for impaired vision. [5]. The patient's CS is determined by the last triplet's letter in which he or she will be able to read two of them. [4]. Striped or sinusoidal tests consist of bright and dark areas called circles. [4]. The most popular is the Vision Contrast Test System (VCTS) or Vistech, which was introduced in the 1980s [18]. It consists of circular gratings in five rows and nine columns, with spatial frequencies of 1.5, 3, 6, 12 and $18 \mathrm{c} / \mathrm{deg}$ and the contrast decreases from left to right. [17] The circular gratings may be vertical positioned $\left(90^{\circ}\right)$ or inclined $15^{\circ}$ counterclockwise or clockwise. It is available in two versions, one for remote and one for close examination. The VCTS 6500 is used for the three-meter long test and is $93 \times 68 \mathrm{~cm}$ in size and the VCTS 6000 is $40 \mathrm{~cm}$ in size $17.5 \times 14 \mathrm{~cm}$ respectively. Depending on the last correct answer for each test series given by the patient, the CSF curve is constructed [5] Figures $6 \& 7$.

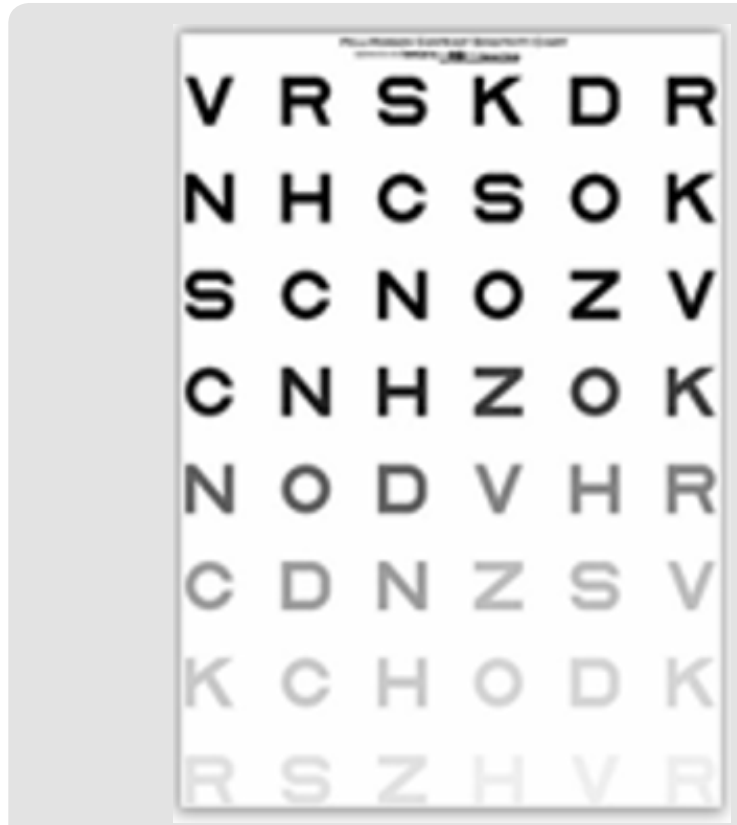

Figure 6: The Pelli-Robson chart.

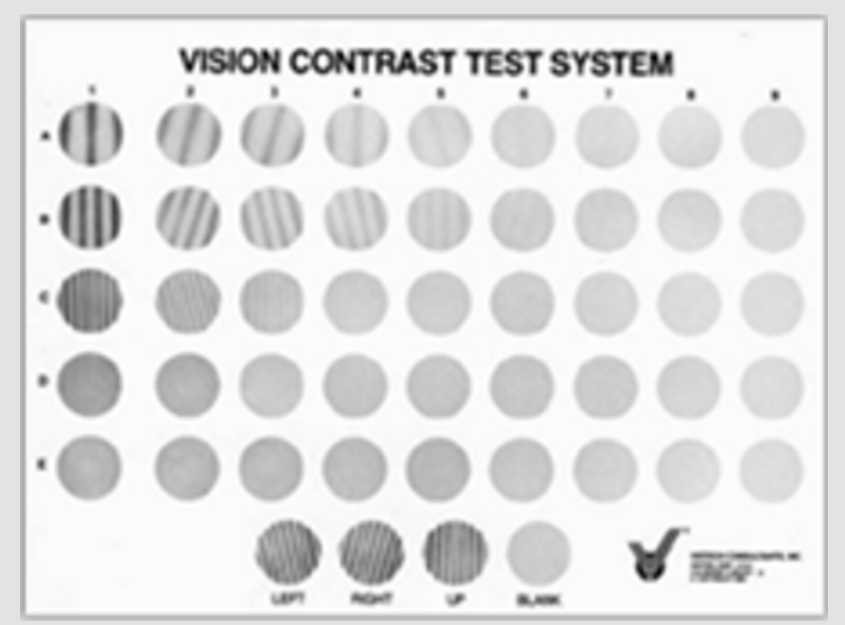

Figure 7: The VCTS chart.

\section{Other Popular Tests for CS}

Bailey-Lovie test: This test, in addition to accurate V.A. measurement, is also used to evaluate CS. Due to the logarithmic size difference between the letters it comprises and the gaps between them in glare, it is possible to determine the CS of the examinee[5,17].Cambridge test: This test is conducted at 6 meters, presenting the subject with a spiral book $(28 \times 22 \mathrm{~cm})$ with two images of the same average brightness, but only one has a grating pattern. The patient is asked to answer which of the two images has a grating pattern. This test detects only $4 \mathrm{c} / \mathrm{deg}[5,17]$. F.A.C.T. test: Functional Acuity Contrast Test- It is almost the same as VCTS and consists of the same number of gratings with the difference in orientation and contrast, but it is conducted at close range $(46 \mathrm{~cm})[4,7]$. MARS test: It is a letter test, at close range $(41-59 \mathrm{~cm})$ and $23 \times 36 \mathrm{~cm}$ in size, with contrast between $0.04-1.92$ log units. 
The letters, as in Pelli-Robson, are equal in size but their contrast is reduced to $0.04 \mathrm{log}$ units per letter. Usually a close correction of 2 diopters is needed [4,19,20]. Test Chart 2000: It is a CS test conducted on an electronic screen. It presents letters or numbers in the same way as the Pelli-Robson test, which decreases in triplicate. The difference is that it is held within one meter of the subject and may require a correction of approximately + 0.75D [4,19]. As with other eye examinations, in the case of CS, measurements must be made under specific lighting conditions. If this is not done, the test will produce results that are not true. As a general rule, ambient lighting should be within $10-30 \%$ of the average brightness of the target [21]. However, each test is different and test conditions should be suggested by the manufacturer / researcher promoting it.

\section{Studies on CS Related to Diseases}

Many conditions (age, myopia, etc.) and eye diseases (diabetes, cataract, glaucoma, etc.) affect CS, just before any change in V.A. is detected. Studies around the world have been conducted by various researchers on CS changes depending on the case and the effect this change has on patients' daily lives. With age, the functions of the body begin to decline and so does CS. Although it has generally not been established by studies in patients with good visual acuity, what exactly neurological changes in age contribute to the loss of CS[22].The frequencies initially affected are the lowest and begin at approximately after the age of 40 [22]. Although myopia is a refractive error, it is a significant factor in effecting CS of the eye. Several studies show that there is a decrease in CSF in myopia, but the role of refractive error is unclear, as various optical factors, such as eye aberration (spherical aberration, diffusion by the crystalline lens), are inserted [23-25].The retina and the macula area are affected by several diseases, such as age-related macular degeneration, diabetes, detachment, central serous retinopathy, macular holes, etc. CS appears weakened to a degree regarding the severity of the disease [26-30]. For example, in the case of macular holes, the less tissue missing, the closer the CS is to the normal (but not completely normal) [30].Nevertheless, CS is definitely affected and usually before V.A. of the patient, in the early stages of the disease (age-related macular degeneration, diabetic retinopathy), causing problems in his quality of the patient life (driving, working etc.) $[27,31,32]$. In the retinal diseases category there are also studies with positive CS results. In some situation it is possible to recover part of the lost CS by restoring the tissue, such as retinal detachment, following surgery [28] or in cases of diabetic macular edema resection $[6,32]$.

Cataracts, as they form a blur to the crystalline lens, are one of the most common causes of CS decline, as they block part of the light from reaching the retina. CS changes even in the early stages of the disease [33] mainly at high frequencies, without necessarily affecting the V.A. from such an early stage[34].Although now successfully treated, many patients live with cataracts for a sufficient period of time until the intraocular lens replace the milky crystalline lens, and therefore with reduced CS [35].Glaucoma has been described by many optometrists and ophthalmologists as the silent thief of sight. Causes damage to ganglion cells that play a key role in the functioning of the human eye's CS and therefore leads to its reduction[22,36].And in the case of open angle glaucoma changes in the CS are observed clinically before the V.A. is affected [36].and in some patients before even reducing their field of vision [37]. Optical neuritis, usually due to multiple sclerosis, affects the optic nerve and consequently the ganglion cell axons and the three pathways of transport of stimuli to the brain (M / P cellular and the $S$ cone response group) [11]. Mostly, color perception is affected by optic neuritis rather than CS, especially if the P pathway is affected $[11,38,39]$. Therefore, the important role of the M pathway in CS is confirmed .

\section{Other Factors That Affect CS}

Intraocular lens used either in cataract surgery or in refractive surgery does not reduce CS [34,40]. Especially in the case of cataracts they certainly improve CS postoperatively, and the possible differences that can be observed in CSF measurements are mainly due to their materials [41] and whether they are spherical or aspherical[42]. In refractive surgery (PRK and Lasik) there is a change in CS postoperatively, mainly at medium and high frequencies, even if V.A. reaches $6 / 6$, [43] and when the pupil's diameter is about $7 \mathrm{~mm}$ the problem is aggravated by the increasing aberrations [44-46]. The problem is now improved with PRK in combination with mitomycin, thinner flaps and Lasik wavefront, but compared to intraocular lenses CS postoperatively is slightly reduced. [46-48]. The purpose of orthokeratology is good daytime vision, without any aids such as glasses or contact lenses. [49]. The application is successful in low and medium myopia. [49]. Specially designed RGP contact lenses are used throughout the night (worn during sleep) to eliminate myopia [49]. The disadvantage of this method is the high order aberrations and the reduction of mesopic CS, thus making night vision particularly difficult [49]. Another factor that affects CS is severe dry eye [50]. In addition to being an unpleasant condition for the patient, in combination with the glare it can reduce the quality of one's vision. The administration of artificial tears usually leads the CS to normal levels [50]. It has been observed in clinical studies that schizophrenia reduces the CS of the sufferer and is associated with deficits in the Magno tract. [51]. Studies have shown a decrease in the CS curve, but no direct interaction with M-pathway, and may be due to the medication patients receive [52]. The immune system of HIV patients is malfunctioning, so they are affected by other viruses that the healthy body would have been able to deal with. Ophthalmologically, abnormalities in CS and color vision are often present in HIV patients [53].

\section{Developments}

New technologies for examining CS are starting to emerge, mainly taking advantage of modern electronic devices. Quick-CSF 
(Quick CSF) promises complete testing in a matter of minutes (2-5min) with fully automated means (handled via a tablet). test [54-60]. Finally using the well-known web browser, Firefox, an innovative CSF Nearby SPARCS test, uses a computer screen and the gray gradations it can perform Figure 8.

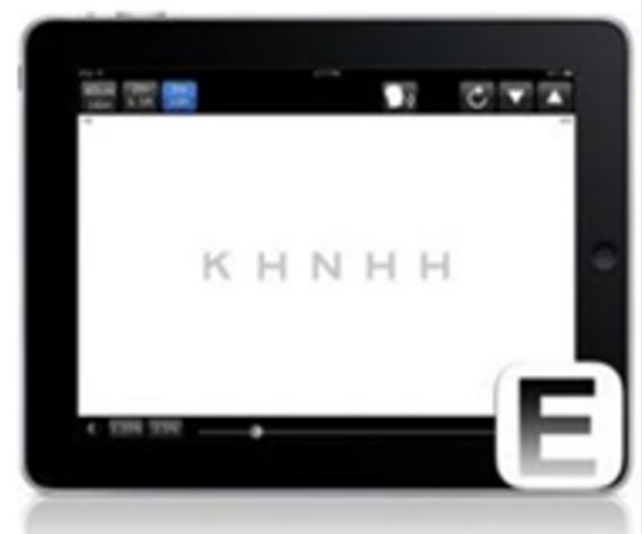

Figure 8: Test CS at iPad.

\section{Discussion}

Vision is one of the most demanding functions of the human brain. The introduction of visual stimuli into the eye and their path from its anatomical structures to its retinal photoreceptors is a condition that is interdependent on many factors. Subsequently, transferring stimuli from the retina to the occipital lobe but also analyzing and deciphering them is a complicated process involving many parts of the brain [61-64]. The case of CS is even more complicated as the roles of the anatomical structures of the optic nerve and the brain that contribute to it have not been fully defined[11]. Each eye is also a separate case, with its own visual aberrations making it even more difficult the study of CS accurately. Finally, the tests used clinically do not necessarily have consistent results, depending on several factors (eye refractive errors, ambient illumination, age, patient concentration - do not cease to be part of the subjective examination), as well as not all of them current tests perform equally valid in each case (e.g. Vistech does not give accurate results after refractive surgery)[7].It is certain that studying the function of vision will always remain a pleasant challenge for scientists in the field. Research and the discovery of new methods for understanding the fascinating parts of the human eye and brain, as well as the connection between them, will not stop.

\section{Acknowledgement}

None

\section{Conflict of Interests}

None

\section{References}

1. Moseley MJ, Hill AR (1994) Contrast sensitivity testing in clinical practice, British Journal of Ophthalmology 78: 795-797.

2. Wright CE, Drasco N (1985) The influence of age on the spatial and temporal contrast sensitivity function, Documenta Ophthalmologica 59: 385-395.

3. Arden GB (1978) The importance of measuring contrast sensitivity in cases of visual disturbance, British Journal of Ophthalmology 62: 198209.

4. Sukha AY, Rubin A (2013) Psychophysical aspects of contrast sensitivity, South African Optometrist 72(2): 76-85.

5. Woods RL, Wood JM (1995) The role of contrast sensitivity charts and contrast letter charts in clinical practice, Clinical and Experimental Optometry 78 (2): 43-57.

6. Farahvash MS, Mahmoudi AH, Farahvash MM, Tabatabaee A, Riazi M, et al. (2008) The impact of macular laser photocoagulation on contrast sensitivity function in patients with clinically significant macular edema, Archives of Iranian Medicine 11(2): 143-147.

7. Hitchcock EM, Dick RB, Krieg EF (2003) Visual contrast sensitivity testing: A comparison of two F.A.C.T. test types, Neurotoxicology and Teratology 26: 271-277.

8. Chung STL, Legge GE (2016) Comparing the Shape of Contrast Sensitivity Functions for Normal and Low Vision, Investigative Ophthalmology and Visual Science 57: 198-207.

9. Pelli DG, Bex P (2013) Measuring contrast sensitivity, VisionResearch 90: $10-14$.

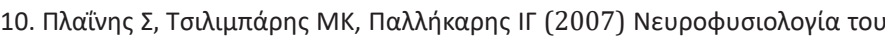

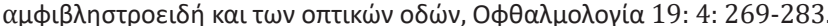

11. Al-Hashmi AM, Kramer DJ, Mullen KT (2011) Human vision with a lesion of the parvocellular pathway: an optic neuritis model for selective contrast sensitivity deficits with severe loss of midget ganglion cell function, Experimental Brain Research 215: 293-305.

12. Mc Anany JJ, Alexander KR (2006) Contrast sensitivity for letter vs. gratings under conditions biased toward parvocellular and magnocellular pathways, Vision Research 46: 1574-1584.

13. Plainis S, Murray IJ (2005) Magnocellular channel subserves the human contrast sensitivity function, Perception 34: 933-940.

14. Weatherhead RG (1980) Use of the Arden grating test for screening British Journal of Ophthalmology 64: 591-596.

15. Mäntyjärvi M, Laitinen T (2001) Normal values for the Pelli- Robson contrast sensitivity test, Journal of Cataract and Refractive Surgery 27: 261-266.

16. Elliot DB, Sanderson K, Conkey A (1990) The reliability of the PelliRobson contrast sensitivity chart, Ophthalmic and Physiological Optics 10: 21-24.

17. Elliot DB, Whitaker D (1992) Clinical contrast sensitivity chart evaluation, Ophthalmic and Physiological Optics 12: 275-280.

18. Ginsburg AP (1984) A new contrast sensitivity vision test chart, American Journal of Optometry \& Physiological Optics 61(6): 403-407.

19. Thayaparan K, Crossland MD, Rubin GS (2007) Clinical assessment of two new contrast sensitivity charts, British Journal of Ophthalmology 91: 749-752.

20. Faye EE (2005) Contrast sensitivity tests in predicting visual function, Internation Congress Series 1282: 521-524.

21. Cox MJ, Norman JH, Norman P (1999) The effect of surround luminance on measurements of contrast sensitivity, Ophthalmic and Physiological Optics 19(5): 401-414. 
22. Mc Kendrick AM, Sampson GP, Walland MJ, Badcock DR (2007) Contrast sensitivity changes due to glaucoma and normal aging: low spatial frequency losses in both magnocellular and parvocellular pathways, Investigative Ophthalmology \& Visual Science 48(5): 2115-2122.

23. Kamiya K, Shimizu K, Iijima A, Kobashi H (2014) Factors influencing contrast sensitivity function in myopic eyes, PLOS ONE 9(11): 1-5.

24. Radhakrishnan H, Pardhan S (2006) Contrast detection in noise with positive and negative defocus in myopes, Vision Research 46: 29492955.

25. Radhakrishnan H, Pardhan S, Calver RI, O'Leary DJ (2004) Effect of positive and negative defocus on contrast sensitivity in myopes and nonmyopes, Vision Research 44: 1869-1878.

26. Keane PA, Patel PJ, Ouyang Y, Chen FK, Ikeji F, et al. (2010) Effects of retinal morphology on contrast sensitivity and reading ability in Neovascular Age-Related Macular Degeneration, Investigative Ophthalmology \& Visual Science 51(11): 5431-5437

27. Bansback N, Czoski-Murray C, Carlton J, Lewis G, Hughes L, et al. (2007) Determinants of health related quality of life and health state utility in patients with age related macular degeneration: the association of contrast sensitivity and visual acuity, Quality of Life Research 16: 533543.

28. Anderson C, Sjöstrand J (1981) Contrast sensitivity and central vision in reattached macula, A study of the function of macula following operation of a retinal detachment involving the macula, Acta Ophthalmologica Scandinavica 59: 161-169.

29. Vaegan, Billson FA (1986) Macular electroretinograms and contrast sensitivity as sensitive detectors of ear maculopathy, Documenta Ophthalmologica 63: 399-406.

30. Mitra S (1985) Spatial contrast sensitivity in macular disorder Documenta Ophthalmologica 59: 247-267.

31. Rashmi S, Varghese RC, Anupama B, Hedge V, Jain R, et al. (2016) Contrast sensitivity in diabetic patients without retinopathy and its correlation with the duration of dibetes and glycemic control, IOSR Journal of Dental and Medical Sciences 15(8): 11-13.

32. Lövestam Adrian M, Svendenius N, Agardh E (2000) Contrast sensitivity and visual recovery time in diabetic patients treated with panretinal photocoagulation, Acta Ophthalmologica Scandinavica 78: 672-676.

33. Friström B, Lundh BL (2000) Colour contrast sensitivity in cataract and pseudophakia, Acta Ophthalmologica Scandinavica 78: 506-511.

34. Montés-Micó R, Alió JL (2003) Distance and near contrast sensitivity function after multifocal intraocular lens implantation, Journal of Cataract and Refractive Surgery 29: 703-711.

35. Owsley C, Stalvey BT, Wells J, Sloane ME, Mc Gwin G (2001) Visua risk factors for crash involvement in older drivers with cataract, Arch Ophthalmol. The JAMA Network 119: 881-887.

36. Richman J, Lorenzana LL, Lankaranian D, Dugar J, Mayer J, et al. (2010) Importance of visual acuity and contrast sensitivity in patients with glaucoma, Arch Ophthalmol. The JAMA Network 128(12): 1576-1582.

37. Zulauf M, Flammer J (1993) Correlation of spatial contrast sensitivity and visual fields in glaucoma, Clinical and Experimental Ophthalmology 231: 146-150.

38. Thurtell MJ, Bala E, Yaniglos SS, Rucker JC, Peachey NS, et al. (2009) Evaluation of optic neuropathy in multiple sclerosis using low-contrast visual evoked potentials, Neurology 73: 1849-1857.

39. Jackson TL, Ong GL, Ripley LG (2004) Orientational contrast sensitivity and chromatic contrast thresholds in multiple sclerosis, American Journal of Ophthalmology 137: 283-286.

40. Pieh S, Weghaupt H, Skorpik C (1998) Contrast sensitivity and glare disability with diffractive and refractive multifocal intraocular lenses, Journal of Cataract and Refractive Surgery 24: 659-662.
41. Peris Martinez C, Artigas JM, Sánchez-Cortina I, Felipe A, Díez-Anjenjo A et al. (2009) Influence of optic quality on contrast sensitivity and visual acuity in eyes with a rigid or flexible phakic intraocular lens, Journal of Cataract and Refractive Surgery 35: 1911-1917.

42. Ishii Y, Okamoto C, Hiraoka T, Okamoto F, Oshika T (2009) Mesopic contrast sensitivity and ocular higher-order aberrations in eyes with conventional spherical intraocular lenses, American Journal of Ophthalmology 148: 298-302.

43. Quesnel NM, Lovasik JV, Ferremi C, Boileau M, Ieraci C (2004) Laser in situ keratomileusis for myopia and the contrast sensitivity function, Journal of Cataract and Refractive Surgery 30: 1209-1218.

44. Tahir HJ, Parry NRA, Brahma A, Ikram K, Muuray IJ (2009) The importance of grating orientation in contrast sensitivity following refractive surgery, Ophthalmic and Physiological Optics 29: 518-525.

45. Oshika T, Tokunaga T, Samejima T, Miyata K, Kawana K, et al. (2006) Influence of pupil diameter on the realation between ocular higher-order aberration and contrast sensitivity after Laser in situ keratomileusis, Investigative Ophthalmology and Visual Science 47(4): 1334-1338.

46. Miraftab M, Hashemi H, Asgari S (2015) Matched optical comparison of 3-year results of PRK-MMC and phakic IOL implantation in the correction of high myopia, Eye 29: 926-931.

47. Tuan KA, Liang J (2006) Improved contrast sensitivity and visual acuity after wavefront-guided laser in situ keratomileusis: In-depth statistical analysis, Journal of Cataract and Refractive Surgery 32: 215-220.

48. Gertnere J, Solomatin I, Sekundo W (2013) Refractive lenticule extraction (ReLEx flex) and wavefront- optimized Femto-LASIK: comparison of contrast sensitivity and high-order aberrations at 1 year, Archives of Clinical and Experimental Ophthalmology 251: 1437-1442.

49. Hiraoka T, Okamoto C, Ishii Y, Takahira T, Kakita T, et al. (2008) Mesopic contrast sensitivity and ocular higher-order aberrations after overnight orthokeratology, American Journal of Ophthalmology 145(4): 645-655.

50. Puell MC, Benítez-del-Castillo JM, Martínez-de-la-Casa J, Sánchez-Ramos C, Vico E, et al. (2006) Contrast sensitivity and disability glare in patients with dry eye, Acta Ophthalmologica Scandinavica 84: 527-531.

51. Slaghuis WL (2004) Spatio-temporal luminance contrast sensitivity and visual backward masking in schizophrenia, Experimental Brain Research 156: 196-211.

52. Skottum BC, Skoyles JR (2007) Contrast sensitivity and magnocellular functioning in schizophrenia, Vision Research 47: 2923-2933.

53. Shah KH, Holland GN, Yu F, Van Natta M, Nusinowitz S (2006) in collaboration with the studies of the ocular complications of AIDS (SOCA) research group, Contrast sensitivity and color vision in HIVinfected individuals without infectious retinopathy, American Journal of Ophthalmology 142(2): 284-292.

54. Rodríguez-Vallejo M, Remón L, Monsoriu JA, Furlan WD (2015) Designing a new test for contrast sensitivity function measurement with iPad, Journal of Optometry 8: 101-108.

55. Adams RJ, Courage ML (2002) Using a single test to measure human contrast sensitivity from early childhood to maturity, Vision Research 42: 1205-1210.

56. Owsley C (2011) Aging and Vision, Vision Research 51(13): 1610-1622.

57. Hargadon DD, Wood J, Twelker D, Harvey EM, Dobson V (2010) Recognition acuity, grating acuity, contrast sensitivity and visual fields in 6-year-old children 128 (1): 70-74

58. Van Gaalen KM, Jansonius NM, Koopmans SA, Terwee T, Kooijman A (2009) Relationship between contrast sensitivity and spherical aberration, Comparison of 7 contrast sensitivity tests with natural and artificial pupils in healthy eyes, Journal of Cataract and Refractive Surgery 35: 47-56. 
59. Liutkevičienė R, Čebatorienẻ D, Liutkevičienẻ G, Jašinskas V, Žaliūniene D (2013) Associations between contrast sensitivity and aging, Medicina (Kaunas) 49(6): 273-277.

60. Elliot DB, Situ P (1998) Visual acuity versus letter contrast sensitivity in early cataract, Vision Research 38: 2047-2052.

61. Ferrer-Blasco T, Montés-Micó R, Cerviño A, Alfonso JF, Fernández-Vega L (2008) Contrast sensitivity after refractive lens exchange with diffractive multifocal intraocular lens implantation in hyperopic eyes, Journal of Cataract and Refractive Surgery 34: 2043-2048.

ISSN: 2574-1241

DOI: $10.26717 /$ BJSTR.2020.27.004439

Pateras E. Biomed J Sci \& Tech Res

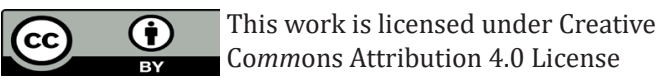

Submission Link: https://biomedres.us/submit-manuscript.php
62. Dorr M, Wille M, Viulet T, Sanchez E, Bex PJ, et al. (2015) Next-generation vision testing: the quick CSF, Current Directions in Biomedical Engineering 1: 131-134.

63. Sun Y, Erdem E, Lyu A, Zanalli C, Wizov SS, et al. (2016) The SPARCS: a novel assessment of contrast sensitivity in patients with corrected refractive error, British Journal of Ophthalmology 10: 1136.

64. Hatch BB, Moshifar M, Ollerton AJ, Sikder S, Mifflin MD (2011) A prospective, contralateral comparison of photorefractive keratectomy (PRK) versus thin-flap LASIK: assessment of visual function, Clinical Ophthalmology 5: 451-457.

$\begin{array}{ll}\text { BIOMEDICAL } & \text { Assets of Publishing with us } \\ \text { RESEARCHES } & \text { - Global archiving of articles } \\ \text { - Immediate, unrestricted online access } & \text { - Rigorous Peer Review Process } \\ & \text { - Authors Retain Copyrights } \\ & \end{array}$

